\title{
Feasibility study of a digital screen-based calming device (MindfulGarden) for bathing-related agitation among LTC residents with dementia
}

\author{
Gloria Gutman PhD ${ }^{\mathrm{a}, \mathrm{b}, *}$, Mojgan Karbakhsh MD ${ }^{\mathrm{a}}$, Avantika Vashisht ${ }^{\mathrm{a}}$, Taranjot Kaur ${ }^{\mathrm{a}}$, \\ Ryan Churchill BA ${ }^{b}$, Amir Moztarzadeh $\mathrm{MA}^{\mathrm{a}}$ \\ ${ }^{a}$ Gerontology Research Centre, Simon Fraser University, Vancouver, BC, Canada; ${ }^{b}$ De- \\ partment of Gerontology, Simon Fraser University, Vancouver, BC, Canada; *Correspond- \\ ing author: gutman@sfu.ca
}

\begin{abstract}
Background: Behavioural and psychological symptoms of dementia (BPSD) are common and disturbing and can deter or disrupt the care process. Bathing is associated with the highest frequency of BPSD, triggering a fear response in dementia patients. As part of a larger feasibility/pilot study, this investigation explored whether exposure to MindfulGarden (MG), a digital screen-based calming device, can minimize BPSD during bathing - an activity well-documented to be problematic for both residents and staff.

Objective: To determine outcome trends of exposure to MG on number and type of BPSD exhibited by residents with dementia during bathing and on staff time to undress, shower and re-dress them.

Method: 8 long-term care home residents $(5 F, 3 M)$ mean age $86.00 \pm 8.16$, diagnosed with dementia and reported by care staff as exhibiting BPSD were observed while being showered in their en-suite bathroom. On Days 1 and 2 staff followed the usual bathing procedure; on Day 3 exposure to MG was added. A 26-item checklist developed in a previous study, based on the Cohen-Mansfield Agitation Inventory and the work of Gutman, MacFadgen and Killam, was used to record type and frequency of BPSD, time of staff entry and exit from the resident's room was recorded, and on Day 3 staff rated MG exposure as having a positive, neutral or negative effect.

Results: Days 1 -2 yielded highly similar results - an average of 4 BPSD per resident and an average bathing time of 13-14 minutes, with the most common BPSD on both days being physical resistance, verbal resistance, screaming, complaining, and strange noises. Subsequent to exposure to MG (Day 3) trends were observed towards reduction in number of BPSD and bathing duration.

Conclusion: $M G$ shows some promise in calming residents, reducing resistance to care, and allowing bathing to proceed more quickly.
\end{abstract}

Keywords: Digital calming device, bathing, long-term care, BPSD, resistance to care

\section{INTRODUCTION}

Dementia is a global epidemic affecting an estimated 50 million persons worldwide, a figure that is projected to increase to 82 million in 2030 and 152 million by 2050 . Each year, nearly 10 million new cases are projected, translating into one every three to four seconds (World Health Organization, 2020). In Canada, more than 402,000 persons are living with dementia (PwD), and each year, 76,000 new cases are diagnosed (Public Health Agency of Canada, 2017). As dementia affects memory, cognitive function, behaviour, and ability to perform daily activities, the impact including human costs extends beyond individual and family levels to the community and global scale (World Health Organization, 2017).

Behavioural and psychological symptoms of dementia (BPSD) represent complexly layered components such as disturbed mood, behaviour, thought and perception exhibited as agitation, aggression, depression, elation, delusions, hallucinations, etc (Finkel, Costa e Silva, Cohen, Miller, \& Sartorius, 1996). BPSD are very common and a major source of suffering, institutionalization, increased costs of care, and significant loss in the quality of life for the PwD, their family, and caregivers (Herrmann et al., 2006; Feast et al., 2016; Kolanowski et al., 2017; Toot, et al., 2017).

Agitation, one of the most disturbing BPSD, and associated with the highest care burden (George, Ferreira, Evans, \& Honeyman, 2020) can be categorized along two dimensions: aggressive vs. non-aggressive, and physical vs. verbal (CohenMansfield, 1996). Bathing is the personal care task most likely to trigger agitation and resistive behaviours and many PwD remain upset even 

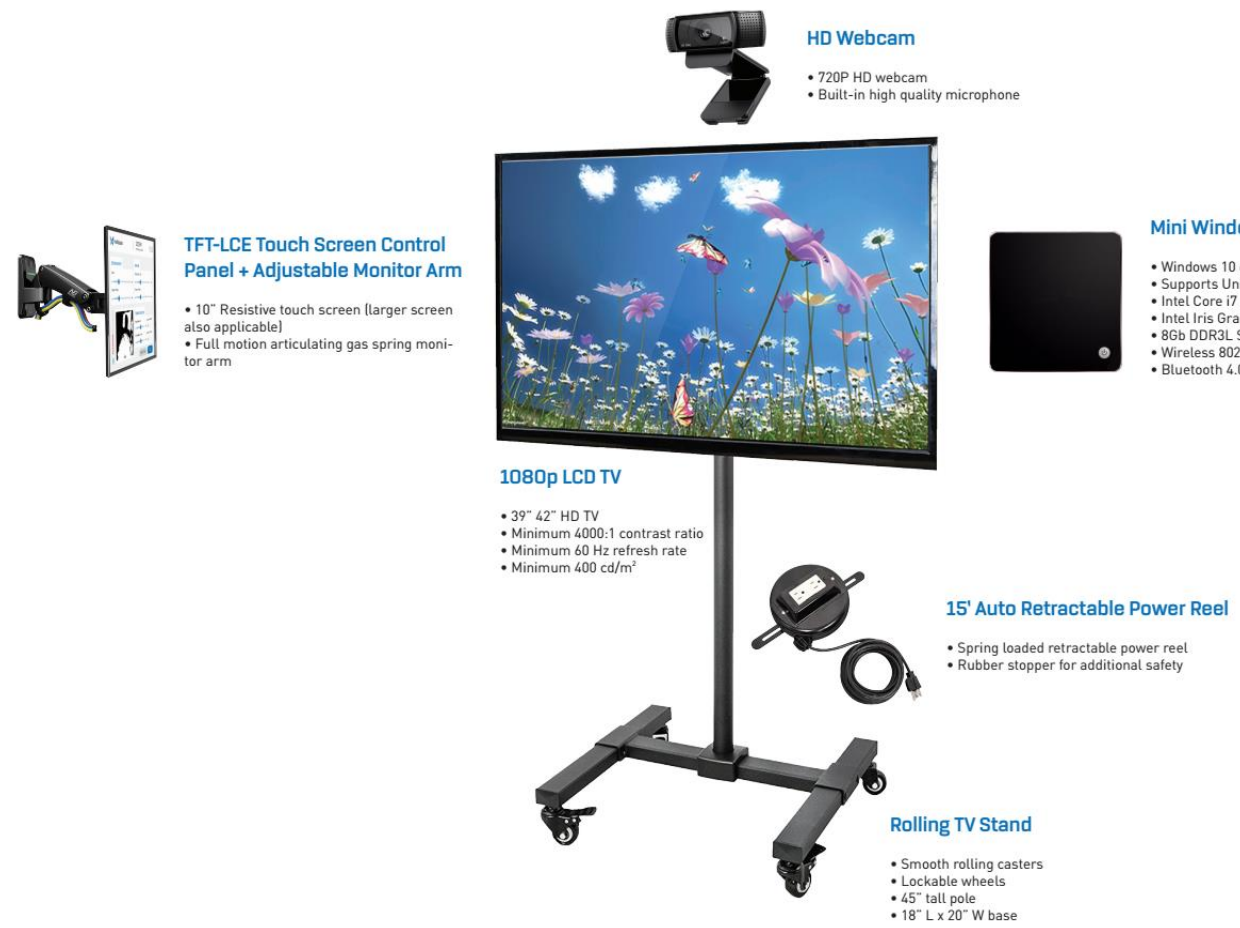

Figure 1. MindfulGarden and its components.

hours after the bath (Barrick et al., 2008). In a study of 1689 baths, $46.1 \%$ involved some form of agitated behaviour (Cooke \& Gutman, 2005).

The initial approach to dementia-related agitation should be identifying any underlying cause such as physical conditions (e.g. pain, constipation, urinary retention) or under/over-stimulation (Aloysi \& Callahan, 2020). Non-pharmacological management of BPSD has gained increased attention due to many concerns including the adverse outcomes associated with prescribed medications (Gitlin, Kales, \& Lyketsos, 2012). These interventions can be behaviour non-specific or targeted; they may directly involve the PwD, the caregiver, and/or the physical environment (Gitlin et al., 2012).

To date, sensory stimulation has been one of the most promising approaches to BPSD alleviation generally and has become increasingly popular in long-term care (LTC) facilities (Lorusso \& Bosch, 2018; Maseda et al., 2018). In this pilot/ feasibility study, we aimed to determine outcome trends of exposure to MindfulGarden - a screen-based digital health device - on the number and type of BPSD exhibited during bathing by PwD living in a care facility environment. More specifically, the focus was on residents who occupy single bedrooms with en-suite bathrooms where they are showered by Residential Care Aides (RCA). Time to complete the task of undressing the resident, assisting them to transfer to a shower chair in the bathroom, showering them, drying and dressing them, and returning them to the bedroom was a secondary outcome for which trends were examined. This study is part of a larger feasibility trial of MindfulGarden conducted in 2018-2020 at a 210 bed LTC facility in British Columbia, Canada. Another part of the study focused on morning and evening personal care, two activities that like bathing, are commonly reported to be problematic both for PwD and for LTC facility staff assisting them (Gutman et al., 2020a). Additionally, the larger study examined MindfulGarden as a tool for calming residents exhibiting BPSD in common areas of the LTC facility (Gutman et al., 2020b).

\section{Methods \\ Participants}

Study participants were 8 residents ( 5 female, 3 male) aged 74-94 with a mean MMSE score of $10.14 \pm 6.94$ screened by the facility's care staff for eligibility based on a diagnosis of dementia and exhibiting BPSD and consented to participate by their Substitute Decision Maker after ethical approval of the study by the Research Ethics Board of Simon Fraser University. Four residents were ambulatory (ID\#20, 23, 26, 29); 4 were not (ID\#9, 14, 19, 21). Duration of stay in LTC ranged from less than 3 years to 10 years. Five received SSRI and/or antipsychotic medications for BPSD management while 3 were not receiving any psychotropic medications. 
Table 1. BPSD categories and behaviours.

\begin{tabular}{|c|c|c|}
\hline & Non-aggressive & Aggressive \\
\hline Physical & $\begin{array}{c}\text { Restlessness } \\
\text { Physical Resistance } \\
\text { Repetitive Mannerisms }\end{array}$ & $\begin{array}{c}\text { Biting } \\
\text { Kicking } \\
\text { Spitting } \\
\text { Slapping } \\
\text { Elbowing } \\
\text { Scratching } \\
\text { Pulling hair } \\
\text { Throwing objects } \\
\text { Pushing/ shoving } \\
\text { Hitting/ punching } \\
\text { Pinching/ squeezing } \\
\text { Threatening gesturing }\end{array}$ \\
\hline Verbal & $\begin{array}{c}\text { Muttering } \\
\text { Demanding } \\
\text { Strange noises } \\
\text { Verbal resistance } \\
\text { Repetitive words } \\
\text { Complaining/negativism }\end{array}$ & $\begin{array}{c}\text { Screaming } \\
\text { Name calling } \\
\text { Verbal threats } \\
\text { Cursing, directed at staff } \\
\text { Hostile, accusatory language }\end{array}$ \\
\hline
\end{tabular}

garden display of layered motion pictures - blossoming flowers and butterflies. The screen is mounted on a wheeled stand (height 54" from floor to top of screen). It is noteworthy that MindfulGarden does not record any identifiable data such as photos, voices or videos from the PwD, the RCAs or the surrounding environment.

\section{Procedures}

Each PwD was showered on the chair in their en-suite bathroom, 5 by one RCA and 3 by two RCAs (due to dementia severity) and observed by a study research assistant (RA) on 3 days. The RCAs were regular unionized staff on the units in which the PwD were residents who, with one exception, had been employed there for an extended period of time. Showering was scheduled by the RCAs based on the PwD's regular bathing interval (once vs. twice per week) and overall conditions at the LTC facility (e.g. flu epidemic precluded observations). Days 1 and 2 provided baseline data: the RCA(s) followed their usual bathing procedure, and the RA (manually) recorded any BPSD exhibited as well as start and end time of undressing/dressing. A 26-item agitated behaviour checklist, developed for a previous bathing study (Cooke, 2006), was used to collect BPSD-related data. The checklist, based on the Cohen-Mansfield Agitation Inventory (CohenMansfield, Marx, \& Rosenthal, 1989) and the work of Gutman, MacFadgen and Killam (1995), lists 3 ers a content generation algorithm to increase decrease the calming on-screen visualizations - a

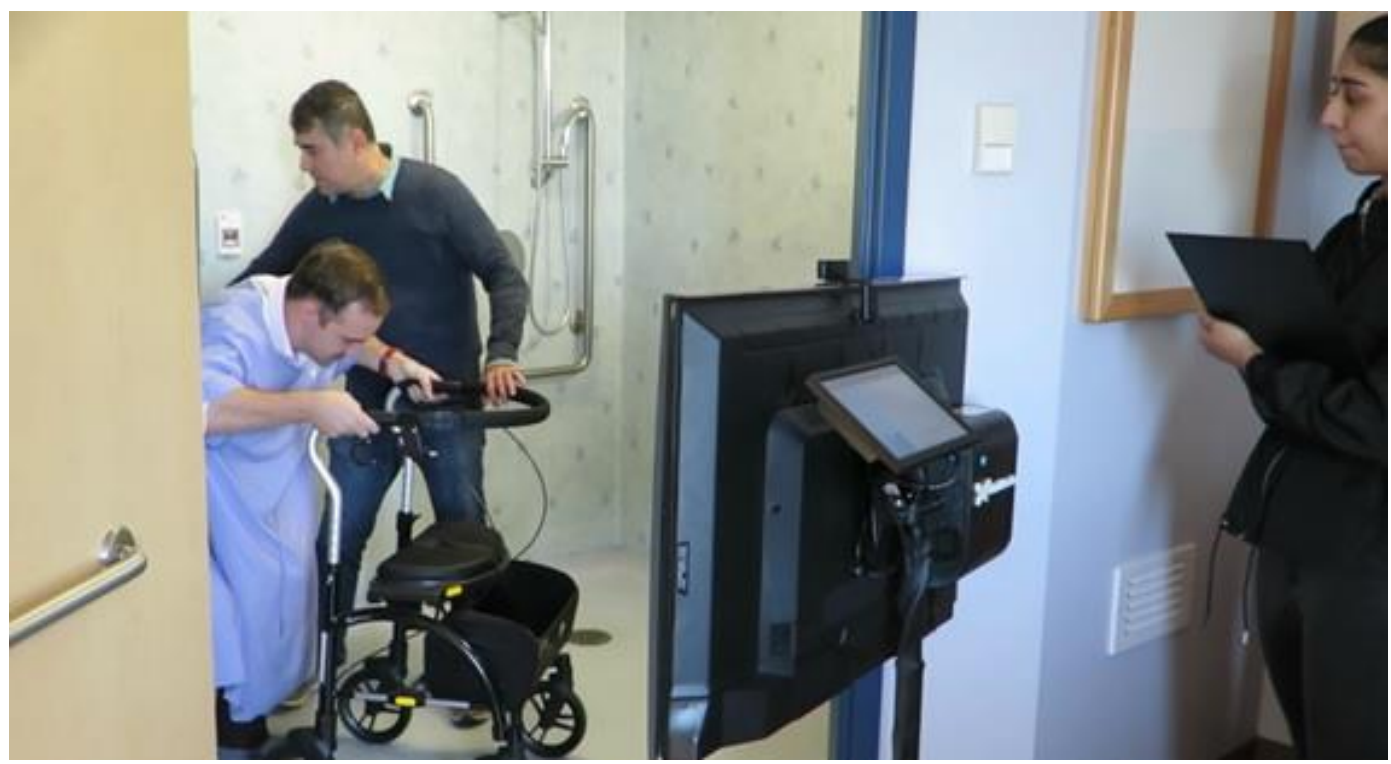

Figure 2. RAs simulating the bathing procedure and positioning of MindfulGarden. 
Table 2. Number of BPSD exhibited by day of observation.

\begin{tabular}{lccc}
\hline ID & Day $\mathbf{1}$ & Day 2 & $\begin{array}{c}\text { Day 3 } \\
\text { (Intervention) }\end{array}$ \\
\hline 9 & 10 & 8 & 5 \\
14 & 5 & 3 & 6 \\
19 & 2 & 3 & 2 \\
20 & 0 & 2 & 0 \\
21 & 3 & 4 & 3 \\
23 & 5 & 3 & 4 \\
26 & 7 & 8 & 3 \\
29 & 1 & 2 & 2 \\
\hline
\end{tabular}

\begin{tabular}{llll}
\hline Mean \pm Sd & $4.12 \pm 3.31$ & $4.12 \pm 2.47$ & $3.12 \pm 1.88$
\end{tabular}

non-aggressive physical, 12 aggressive physical, 6 non-aggressive verbal and 5 aggressive verbal BPSD. A total score was calculated by summing the number of observed behaviours (Table 1).

On Day 3, MindfulGarden was wheeled into the PwD's bedroom and activated when the RCA began removing the PwDs clothes. When the PwD and RCA(s) entered the en-suite bathroom, MindfulGarden was moved with them and was positioned at the bathroom door, facing the PwD (Figure 2). The RA drew attention to the screen ('verbal prompting') if the gaze was not on the screen. Bathing duration (from the time the RCA started to remove the PwD's clothing until the PwD was fully dressed) and the number and type of BPSD exhibited on Day 3 were recorded and compared with the mean of Days 1 and 2. The effect of exposure to MindfulGarden was also assessed by obtaining a rating from the $\mathrm{RCA}(\mathrm{s})$ who showered them as to whether it had a positive, neutral or negative impact on BPSD.

\section{Statistical analysis}

Each BPSD on the checklist was considered a binary variable and was coded 1 if exhibited at least once during the time the RCA(s) were in the resident's room. Thus, the overall BPSD on each observation could range from 0 to 26. IBM SPSS version 22 was implemented for statistical

Table 3. Bathing duration (minutes) by day of observation.

\begin{tabular}{lccc}
\hline ID & Day 1 & Day 2 & $\begin{array}{c}\text { Day 3 } \\
\text { (intervention) }\end{array}$ \\
\hline 9 & 13 & 14 & 12 \\
14 & 10 & 13 & 16 \\
19 & 12 & 12 & 8 \\
20 & 9 & 10 & 7 \\
21 & 19 & 17 & 10 \\
23 & 10 & 13 & 8 \\
26 & 23 & 19 & 10 \\
29 & $*$ & $*$ & $*$
\end{tabular}

\begin{tabular}{llll}
\hline Mean \pm Sd & $13.71 \pm 5.28$ & $14.00 \pm 3.05$ & $10.14 \pm 3.08$
\end{tabular}

*The RA noted that on Day 3, an RCA who was new to the job was showering resident $\# 29$, and the bathing duration increased from 11 minutes (on Days 1 and 2) to 17 minutes on Day 3. Bathing duration for this PwD has been excluded from the analysis. analysis using descriptive statistics and relevant non-parametric tests (Spearman's rho for testing association between BPSD number and bathing duration; Kruskal-Wallis for BPSD categories and bathing duration; Mann-Whitney $U$ for comparing bathing duration in residents exhibiting both aggressive and non-aggressive verbal and/or physical BPSD (AVP and NAVP) and those exhibiting NAVP only; and also for comparing bathing duration in residents with positive vs. neutral response to MG; Wilcoxon Signed-Ranks for comparing bathing duration between Days 2 and 3 and Friedman test for comparing bathing duration across 3 Days). P-value less than 0.05 was considered statistically significant and between 0.05-0.1 marginally significant (Weil, 2017).

\section{Results}

On Day 1, 1 exhibited no BPSD, 6 both AVP and NAVP and 1 only NAVP. The mean number of BPSD was $4.12 \pm 3.31$ (Table 2). The mean bathing duration was $13.71 \pm 5.28$ minutes (Table 3). The most common types of BPSD exhibited were physical resistance (4 residents), verbal resistance, screaming, cursing directed at the staff, hitting/punching, and hostile/accusatory language (3 residents each), threatening gestures, complaining/negativism, and strange noises (2 residents each). There were no significant associations between BPSD number and bathing duration (Spearman's rho $=0.53, \mathrm{P}$ value $=0.224$ ) or BPSD categories and bathing duration (KruskalWallis test, $\mathrm{P}$ value $=0.130$ ).

On Day 2, 4 exhibited both AVP and NAVP and 4 NAVP only. The mean number of BPSD was $4.12 \pm 2.47$. The mean bathing duration was $14.00 \pm 3.05$ minutes. The most common types of BPSD exhibited were physical resistance (5 residents), verbal resistance and strange noises (4 residents each), and screaming (3 residents). There was a marginally significant difference between the mean bathing duration in residents exhibiting both AVP and NAVP $(15.75 \pm 2.75)$ and those exhibiting NAVP only (11.67 \pm 1.53 ) (Mann-Whitney $U$ test, $P$ value $=0.05)$. Also, BPSD number and bathing duration were significantly correlated (Spearman's rho=0.91, P value=0.001) .

On Day 3, when MindfulGarden exposure took place, 1 exhibited no BPSD, 5 both AVP and NAVP, and 2 only NAVP. The mean BPSD was $3.12 \pm 1.88$ and the mean bathing duration was $10.14 \pm 3.08$. The most common types of BPSD exhibited on Day 3 were physical resistance (5 residents), verbal resistance (4 residents), and screaming and complaining/negativism (3 residents 
Table 4. BPSD type, impact assessment and justification by participant and observation day.

\begin{tabular}{lccccc}
\hline ID & Day 1 & Day 2 & $\begin{array}{c}\text { Day 3 } \\
\text { (intervention) }\end{array}$ & $\begin{array}{c}\text { Impact assessment } \\
\text { by RCAs* }\end{array}$ & Justification \\
\hline 9 & $\begin{array}{c}\text { AP \& AV \& NAP } \\
\text { \& NAV }\end{array}$ & $\begin{array}{c}\text { AP \& AV \& NAP \& } \\
\text { NAV }\end{array}$ & AV \& NAP \& NAV & Neutral & $\begin{array}{c}\text { PwD did not pay attention to MG, even } \\
\text { when prompted by the RA. }\end{array}$ \\
\hline 14 & AV \& AP \& NAP & AP \& AV \& NAV & AV \& NAP \& NAV & Positive & $\begin{array}{c}\text { Less screaming than usual. No } \\
\text { complaining, PwD distracted by MG. }\end{array}$ \\
\hline 19 & AP \& NAP & NAP \& NAV & AP \& NAP & Positive & MG distracted the PwD a bit. \\
\hline 20 & No BPSD & NAP \& NAV & No BPSD & Neutral & PwD did not pay attention to MG. \\
\hline 21 & AV \& NAP & AV \& NAP \& NAV & AV \& NAP & Neutral & $\begin{array}{c}\text { MG did not have any effect on } \\
\text { behaviours of PwD. }\end{array}$ \\
\hline 23 & AP \& AV \& NAV & NAP \& NAV & AV \& NAP \& NAV & Neutral & $\begin{array}{c}\text { PwD expressed disinterest and expressed } \\
\text { it verbally after being redirected to MG. }\end{array}$ \\
\hline $\begin{array}{l}26 \\
\text { AP \& AV \& NAP } \\
\text { 29 NAV }\end{array}$ & AP \& AV \& NAP \& & NAV & NAV & Positive & $\begin{array}{c}\text { PwD exhibited less verbal and physical } \\
\text { resistance. }\end{array}$ \\
$\begin{array}{l}\text { AP: Aggressive Physical BPSD; NAP: Non-Aggressive Physical BPSD; } \\
\text { AV: Aggressive Verbal, NAV: Non-Aggressive Verbal BPSD } \\
\text { * RCA: Residential Care Aides }\end{array}$ & NAP \& NAV & Positive & MG distracted the PwD. \\
\hline
\end{tabular}

each). MG exposure was rated as positive in 4 and neutral in 4 (Table 4).

While across the three days there was no statistically significant difference in the number of BPSD (Friedman test, $P$ value $=0.47$ ), there was a marginally significant difference in bathing duration (Friedman Test, $\mathrm{P}$ value $=0.054$ ). Further analysis indicated a marginally significant reduction in bathing duration between Days 2 and 3 (Wilcoxon Signed-Ranks Test, P value=0.051).

No significant differences were detected between residents rated as having had positive vs. neutral responses to MG. On Day 3, the mean number of BPSD exhibited by those rated with positive response was $3.25 \pm 1.89$; among those with neutral response $3.00 \pm 2.16$ (Mann-Whitney test, $P$ value $=0.886$ ). The mean duration of bathing in residents with positive response was 11.33 \pm 4.16 ; in those with neutral effect $9.25 \pm 2.22$ (Mann-Whitney test, $P$ value $=0.629$ ).

\section{Discussion}

In this feasibility study, the outcome trends of BPSD and bathing duration after exposure to an interactive digital behaviour modification device were investigated. The BPSD targeted in this trial were the behaviours arising due to agitation (including verbal aggressive, verbal non-aggressive, physically aggressive and physical non-aggressive behaviours). Agitation is often the most challenging BPSD as it can remarkably disrupt dementia care. To this end, most intervention trials for alleviating BPSD have been performed for agitation (Tible, Riese, Savaskan, \& von Gunten, 2017).

The most common agitated behaviours observed in this trial were physical and verbal resistance, with the pattern being the same on control and intervention days. In a similar study, the most commonly displayed BPSD exhibited during bathing were physical resistance, complaining/ negativism, verbal resistance, and restlessness (Cooke, 2006). In another study that focused only on physical aggressive behaviours during bathing, the most common type was hitting and attempting to hit (Somboontanont et al., 2004).

The mean number of BPSD exhibited by each PwD showed a decreasing trend after exposure to MindfulGarden, suggesting that the device was achieving its aim of calming PwD during bathing. The study also yielded a positive trend in reducing the duration of the bathing procedure.

As MindfulGarden is a novel device, there are not many studies in the literature to compare the findings with, still, based on its mechanism of action, it might be categorized as an 'individualized sensory stimulation' device. Other devices and approaches in the sensory stimulation category used with PwD include Snoezelen which is based on the 'Model of Imbalance in Sensoristasis' (MIS) (Sánchez, et al., 2013; Lorusso \& Bosch, 2018; Maseda et al., 2018; Prins, et al., 2020;) and Project Soothe (with the online gallery added to an app-called CogniCare) (Wilson, et al., 2018; Lorca-Cabrera et al., 2020). Using the MIS model, Kovach (2000) postulates that agitated behaviours may be initiated or escalated when there is an imbalance between sensory-stimulating and sensory-calming activity - a state commonly occurring in institutionalized PwD. Interventions facilitating optimum sensoristasis can alleviate intrapsychic discomfort and decrease agitated behaviours. Working through stimulating the primary senses without relying on intellectual abilities or cognitive functions makes multisensory stimulation an ideal approach for reaching persons with advanced dementia (Kovach et al., 2004; Sánchez,et al., 2013; Cheng, Baker, \& Dursun, 2019). The nature-like visualizations generated by MindfulGarden resemble photographic sky compositions (e.g. SkyCeilings ${ }^{\text {TM }}$ ) which have shown some promising results in preventing delirium among PwD in an emergency room setting (Feldman, Widmer, Connolly, \& Takher, 2017). 
One distinguishing difference between our approach and sensory stimulation interventions such as Snoezelen, Project Soothe, and sky compositions is that MindfulGarden uses the Unity game engine (Unity Technologies, San Francisco, $\mathrm{CA}$ ) to generate the underlying software algorithms and create calming 3D objects and handle their interactions. 'Serious games' are becoming a rapidly growing platform to provide novel solutions for treatment, stimulation, and rehabilitation to PwD (Manera et al., 2017). Bouchard, et al proposed a set of specific guidelines for designing and implementing effective serious games for PwD, emphasizing that in-game features should fit the patient's profile (Bouchard, Imbeault, Bouzouane, \& Menelas, 2012). For instance, in advanced dementia, PwD are very distractible as they cannot suppress the natural tendency to attend to new stimuli. This inability to disregard new stimuli might be so extreme as to render them "stimulus-bound" (Kaufman, Geyer, \& Milstein, 2016). MindfulGarden uses this distractibility to involve them in a game that PwD might not perceive themselves as actually playing.

Another novelty in our study is in using private (en-suite) bathrooms as the study setting. Although shared bathing areas with bathtubs have up to now been the most common bathing setting within LTC facilities (Sloane et al., 1995), this might change after the COVID-19 pandemic as multi-bed rooms are phased out - a recommended means of infection prevention. A cohort study of 627 LTC facilities in Ontario, Canada showed that the incidence rate ratio for COVID-19-related death among LTC residents was 13 times higher than that among community-dwelling adults age 69 and over (Fisman, Bogoch, Lapointe-Shaw, McCready, \& Tuite, 2020). These alarming figures point to a trajectory toward private rooms/bathrooms in nursing homes in the future.
Our study had some limitations. The small number of PwD who were eligible and consented to participation limited the statistical power of the study. As most PwD tended to face downwards during showering or closed their eyes, exposure to MindfulGarden could only take place before or after the actual shower, limiting the feasibility of its use as a calming device to before and after the shower.

Further, as the nature of bathing is intimate and private, the PwD may misinterpret the best intentions of the caregiver as a threat to personal safety and dignity, and react with resistance and rejection of care (D'Hondt, Kaasalainen, Prentice, \& Schindel Martin, 2012).

As noted by one of the RAs and explained under Table 3, shower duration increased from 11 minutes on Days 1 and 2 to 17 minutes on Day 3 for one resident (\#29), when a new RCA showered that individual. Future studies (with a larger number of participants) can examine the role of potential confounding factors in shower duration such as RCA experience and familiarity with the resident as well as the severity of dementia. Further, multisensorial stimulation techniques have been effective in reducing agitation and disruptive behaviour during sessions and immediately afterwards; however, there is a need for future studies to examine their long-term effects on agitation of PwD (Tible et al., 2017). The addition of sound to MindfulGarden also needs to be explored to determine if it increases its ability to capture and sustain the attention of PwD.

\section{Conclusion}

Exposure to MindfulGarden led to decreasing trends in BPSD and bathing duration among PwD in an LTC facility. This effect which seems to be induced through sensory stimulation and/ or distraction needs to be replicated in future studies with a larger and multi-site sample.

\section{References}

Aloysi, A. S., \& Callahan, E. H. (2020). Behavioral and Psychiatric Symptoms in Dementia (BPSD). In: A. Chun (Ed.), Geriatric Practice.A Competency Based Approach to Caring for Older Adults (pp. 223-236). Springer.

Barrick, A. L., Radder, Barrick, A. L., Joanne, R., Hoeffer, B., Sloane, P. D., Biddle, S. (Eds.). (2008). Bathing Without a Battle: Person-Directed Care of Individuals with Dementia. New York: Springer Publishing Company

Bouchard, B., Imbeault, F., Bouzouane, A., \& Menelas, B.-A. J. (2012). Developing Serious Games Specifically Adapted to People Suffering from Alzheimer BT - Serious Games Development and Applications. In M. Ma, M. F. Oliveira, J. B. Hauge, H. Duin, \& K.-D. Thoben (Eds.) (pp. 243-254). Berlin, Heidelberg: Springer Berlin Heidelberg.

Cheng, C., Baker, G. B., \& Dursun, S. M. (2019). Use of

multisensory stimulation interventions in the treatment of major neurocognitive disorders. Psychiatry and Clinical Psychopharmacology, 29(4), 916-921. https://doi.org/10.1080/24750573.2019.1699738

Cohen-Mansfield, J. (1996). Conceptualization of agitation: results based on the Cohen-Mansfield agitation inventory and the agitation behavior mapping instrument. International Psychogeriatrics, 8(s 3), 309-315.

Cohen-Mansfield, J., Marx, M. S., \& Rosenthal, A. S. (1989). A description of agitation in a nursing home. Journal of Gerontology, 44(3), M77-M84.

Cooke, H. (2006). Organizational and physical environmental correlates of bathing-related agitation in dementia special care units (master's thesis). Simon Fraser University, Vancouver, British Columbia, Canada. Retrieved from http://summit.sfu.ca/item/2377

Cooke, H., \& Gutman, G. (2005). Improving the bathing experience for residents with dementia. Canadian 
Nursing Home, 16(2).

D'Hondt, A., Kaasalainen, S., Prentice, D., \& Schindel Martin, L. (2012). Bathing residents with dementia in long-term care: Critical incidents described by personal support workers. International Journal of Older People Nursing, 7(4), 253-263. https://doi. org/10.1111/j.1748-3743.2011.00283.x

Feast, A., Moniz-Cook, E., Stoner, C., Charlesworth, G., \& Orrell, M. (2016). A systematic review of the relationship between behavioral and psychological symptoms (BPSD) and caregiver well-being. International Psychogeriatrics, 28(11), 1761-1774. https://doi.org/10.1017/S1041610216000922

Feldman, F., Widmer, M., Connolly, T., \& Takher, A. (2017). Clinical impacts of emergency department patients' exposure to photographic sky compositions. In Poster presentation at: Fraser Health 4th Annual Patient Experience Conference. Surrey, BC.

Finkel, S. I., Costa e Silva, J., Cohen, G., Miller, S., \& Sartorius, N. (1996). Behavioral and psychological signs and symptoms of dementia: A consensus statement on current knowledge and implications for research and treatment. International Psychogeriatrics, 8(SUPPL. 3), 497-500. https://doi. org/10.1017/S1041610297003943

Fisman, D. N., Bogoch, I., Lapointe-Shaw, L., McCready, J., \& Tuite, A. R. (2020). Risk Factors Associated With Mortality Among Residents With Coronavirus Disease 2019 (COVID-19) in Long-term Care Facilities in Ontario, Canada. JAMA Network Open, 3(7), e2015957. https://doi.org/10.1001/jamanetworkopen.2020.15957

George, C., Ferreira, N., Evans, R., \& Honeyman, V. (2020). A systematic review of the association between individual behavioural and psychological symptoms in dementia and carer burden. Working with Older People, 24(3), 181-203. https://doi. org/10.1108/WWOP-06-2020-0024

Gitlin, L. N., Kales, H. C., \& Lyketsos, C. G. (2012). Managing behavioral symptoms in dementia using nonpharmacologic approaches: an overview. JAMA: The Journal of the American Medical Association, 308(19), 2020.

Gutman, G., MacFadgen, L., \& Killam, J. (1995). Psychogeriatric client identification project - Phase 1 Final Report. Victoria: Continuing Care Division, B.C. Retrieved from http://summit.sfu.ca/item/539

Gutman, G., Vashisht, A., Kaur, T., Churchil, R., Moztarzadeh, A., \& Karbakhsh, M. (2020a). Feasibility Study of a Digital Screen-Based Calming Device for Managing BPSD During Care. In Innovation in Aging; 4(Suppl 1), 755.

Gutman, G., Vashisht, A., Kaur, T., Churchil, R., Moztarzadeh, A., \& Karbakhsh, M. (2020b). Feasibility study of a digital screen-based calming device on disruptive BPSD in shared areas of an LTC facility. Gerontechnology, 19(0), 1. https://doi.org/https:// doi.org/10.4017/gt.2020.19.s.70134

Herrmann, N., Lanctôt, K. L., Sambrook, R., Lesnikova, N., Hébert, R., Mccracken, P., ... Nguyen, E. (2006). The contribution of neuropsychiatric symptoms to the cost of dementia care. International Journal of Geriatric Psychiatry, 21(10), 972. https:// doi.org/10.1002/gps.1594
Kaufman, D. M., Geyer, H. L., \& Milstein, M. J. (2016). Kaufman's Clinical Neurology for Psychiatrists E-Book. Amsterdam, Netherlands: Elsevier Health Sciences.

Kolanowski, A., Boltz, M., Galik, E., Gitlin, L. N., Kales, H. C., Resnick, B., ... Scerpella, D. (2017). Determinants of behavioral and psychological symptoms of dementia: A scoping review of the evidence. Nursing Outlook, 65(5), 515-529. https://doi. org/10.1016/j.outlook.2017.06.006

Kovach, C. R. (2000). Sensoristasis and Imbalance in Persons with Dementia. Journal of Nursing Scholarship, 32(4), 379-384.

Kovach, C. R., Taneli, Y., Dohearty, P., Schlidt, A. M., Cashin, S., \& Silva-smith, A. L. (2004). Effect of the BACE Intervention on Agitation of People With Dementia. The Gerontologist, 44(6), 797-806.

Lorca-Cabrera, J., Martí-Arques, R., Albacar-Riobóo, N., Raigal-Aran, L., Roldan-Merino, J., \& Ferré-Grau, C. (2020). Mobile Applications for Caregivers of Individuals with Chronic Conditions and/or Diseases: Quantitative Content Analysis. International Journal of Medical Informatics, 145(November 2020), 104310. https://doi.org/10.1016/j.ijmedinf.2020.104310

Lorusso, L. N., \& Bosch, S. J. (2018). Impact of Multisensory Environments on Behavior for People With Dementia: A Systematic Literature Review. Gerontologist, 58(3), e168-e179. https://doi.org/10.1093/ geront/gnw168

Manera, V., Ben-Sadoun, G., Aalbers, T., Agopyan, H., Askenazy, F., Benoit, M., ... Robert, P. (2017). Recommendations for the use of serious games in neurodegenerative disorders: 2016 Delphi Panel. Frontiers in Physiology, 8(JUL), 1-10. https://doi. org/10.3389/fpsyg.2017.01243

Maseda, A., Cibeira, N., Lorenzo-López, L., GonzálezAbraldes, I., Buján, A., De Labra, C., \& MillánCalenti, J. C. (2018). Multisensory Stimulation and Individualized Music Sessions on Older Adults with Severe Dementia: Effects on Mood, Behavior, and Biomedical Parameters. Journal of Alzheimer's Disease, 63(4), 1415-1425. https://doi.org/10.3233/ JAD-180109

MindfulGarden Digital Health, Inc. (2021). Retrieved January 22, 2021, from https://mindfulgarden.com/

Public Health Agency of Canada. (2017). Dementia in Canada, including Alzheimer's disease. Highlights from the Canadian Chronic Disease Surveillance System (Fact Sheet). Retrieved January 22, 2021, from https://www.canada.ca/en/public-health/services/ publications/diseases-conditions/dementia-highlights-canadian-chronic-disease-surveillance.html

Sánchez, A., Millán-Calenti, J. C., Lorenzo-López, L., \& Maseda, A. (2013). Multisensory stimulation for people with dementia: A review of the literature. American Journal of Alzheimer's Disease and Other Dementias, 28(1), 7-14. https://doi. org/10.1177/1533317512466693

Sloane, P. D., Honn, V. J., Dwyer, S. A. R., Wieselquist, J., Cain, C., \& Myers, S. (1995). Bathing the Alzheimer's patient in long term care: Results and recommendations from three studies. American Journal of Alzheimer's Disease and Other Dementias, 10(4), 3-11. https://doi. org/10.1177/153331759501000403 


\section{MindfulGarden for managing bathing-related agitation}

Somboontanont, W., Sloane, P. D., Floyd, F. J., Holditch-Davis, D., Hogue, C. C., \& Mitchell, C. M. (2004). Assaultive behavior in Alzheimer's disease: Identifying immediate antecedents during bathing. Journal of Gerontological Nursing, 30(9), 22-29.

Tible, O. P., Riese, F., Savaskan, E., \& von Gunten, A. (2017). Best practice in the management of behavioural and psychological symptoms of dementia. Therapeutic Advances in Neurological Disorders, 10(8), 297-309. https://doi. org/10.1177/1756285617712979

Toot, S., Swinson, T., Devine, M., Challis, D., \& Orrell, M. (2017). Causes of nursing home placement for older people with dementia: A systematic review and meta-analysis. International Psychogeriatrics, 29(2), 195-208. https://doi.org/10.1017/ S1041610216001654

Weil, J. (2017). Research design in aging and social gerontology: Quantitative, qualitative, and mixed methods. Taylor \& Francis.

Wilson, A. C., Schwannauer, M., McLaughlin, A., Ashworth, F., \& Chan, S. W. Y. (2018). Vividness of positive mental imagery predicts positive emotional response to visually presented Project Soothe pictures. British Journal of Psychology, 109(2), 259-276. https://doi.org/10.1111/bjop.12267

World Health Organization. (2017). Global action plan on the public health response to dementia 2017 - 2025. Geneva: World Health Organization. Retrieved January 22, 2021, from http://www.who. int/mental_health/neurology/dementia/action_ plan_2017_2025/en/

World Health Organization. (2020). Dementia: key facts. Retrieved January 22, 2021, from https:// www.who.int/health-topics/dementia $\#$ tab=tab_1 